\title{
Risk factors of poor prognosis after whiplash injury
}

\author{
Prof. Samy Suissa, PH.D.*
}

\begin{abstract}
Whiplash, a common injury following motor vehicle crashes, is associated with high costs and a prognosis that is variable and difficult to predict. In this paper, we review findings from the Quebec cohort epidemiological study on predictive factors of recovery from whiplash injury after a motor vehicle crash.

We formed a population-based incident cohort of all 4,759 individuals who sustained a whiplash injury resulting from a motor vehicle crash in the province of Québec, Canada, in 1987, and followed these patients for up to seven years. The data were obtained from the universal automobile insurance plan (SAAQ) that covers all seven million residents of the Province for all vehicular-related injuries. From this cohort, we formed the cohort of 3,014 for whom a police report was completed. For this cohort, we obtained data on crash-related factors directly from the police report. We also formed the cohort of 2,627 subjects who had strictly a whiplash injury, without associated injuries. For this cohort, the data on signs and symptoms were obtained from the medical charts kept by the SAAQ. For both cohorts, data on the outcome, the recovery time from whiplash, was obtained from the SAAQ databases.

The crash-related cohort study found that socio-demographic factors associated with a longer recovery from whiplash include older age, female sex, having dependents and not being employed full time and that each decreases the rate of recovery by 14 to 16 per cent. Factors related to the crash conditions indicate that being in a truck or bus,
\end{abstract}

with a decrease of $52 \%$ in the rate of recovery, being a passenger in the vehicle $(15 \%)$, colliding with a moving vehicle $(16 \%)$, and a side or frontal collision (15\%) all decrease the rate of recovery. We introduce a combined risk score that predicts longer recovery.

In the cohort of subjects with signs and symptoms, the median recovery time was 32 days and $12 \%$ of subjects had still not recovered after 6 months. The signs and symptoms that were found to be independently associated with a slower recovery from whiplash, besides female gender and older age, were neck pain on palpation; muscle pain; pain or numbness radiating from neck to arms, hands or shoulders; and headache. Together, the presence of all these factors in females aged 60 predicted a median recovery time of 262 days, compared with 17 days for younger males aged 20 who do not have any of these factors. In contrast, using the Quebec classification of signs and symptoms, the median recovery time varied from 17 to 123 days.

We conclude that several socio-demographic and crash-related factors, as well as several signs and symptoms, including a combination of specific musculoskeletal and neurological ones that whiplash patients present with, are predictive of a longer recovery period. These patients should be targeted for an early intervention programme aimed at managing whiplash patients with a poor prognosis.

Key Words: Epidemiology; Motor vehicle crash; Prognosis; Soft tissue injury; Trauma.

\section{Introduction}

Whiplash is a common injury that occurs among motor vehicle occupants involved in collisions. It was originally named to describe the result of a rapid hyper-extension and flexion of the muscles of the neck (4). Its incidence varies between 70 per 100,000 yearly in Quebec (1,5) and 106 per 100,000 in Australia (6). Its cost to the health care system is high, with an estimated \$2,500 (1987 CAD) in indirect costs per subject (1). One of the challenges of managing a patient with a whiplash injury is the high variability and low predictability of the prognosis of the injury (7). The studies on the duration of this condition are inconsistent, with results such as $27 \%$ still affected at six months (8), 26\% at one year (9), $44 \%$ at two years, and $7 \%$ still unable to return to work at two years (10).

Several socio-demographic and crash-related factors are associated with a longer recovery from whiplash (2). However, the results for certain factors, such as seat-belt use, for example, are often contradictory $(2,11-13)$. With respect to the predictive ability of initial signs and symptoms, studies are highly variable in their results. Patients present with a multitude of signs and symptoms that range from simple neck pain to combinations of several musculoskeletal and neurological manifestations $(8,10,14-16)$. The profile of presenting symptoms varies widely across studies, with, for example, paresthesia present in $62 \%$ of patients versus $13 \%$ and auditory symptoms in $18 \%$ versus $4 \%(8,10,16)$. Their predictive ability is uncertain, as finger paresthesia, the presence of neck stiffness and muscle spasm, and pain in the upper limbs and back were found to be associated with a delay in recovery $(8,16,17)$. These studies are limited by the small number of subjects, less than 100, and an unclear time zero for the cohort. The Quebec Whiplash-Associated Disorders Task Force proposed a classification of whiplash-associated signs and symptoms, the Quebec classification, as a tool of grading severity (5). Our study clarified these discrepancies in the context of a population-based evaluation (3)

In this article, we review findings from the Quebec cohort epidemiological study on predictive factors of recovery from whiplash injury after a motor vehicle crash. We review the predictive ability of socio-demographic factors, several crash-

*Professor, Department of Epidemiology and Biostatistics, McGill University, Montreal, Quebec, Canada

Correspondence: Dr S Suissa, Department of Epidemiology and Biostatistics, Division of Clinical Epidemiology, Royal Victoria Hospital, 687 Pine

Avenue West, R4.29, Montreal, Quebec H3A 1A2. Telephone 514-843-1564, fax 514-843-1493, e-mail samy.suissa@clinepi.mcgill.ca 
related factors, as well as the initial signs and symptoms reported after the crash, on the duration of recovery.

\section{METHODS}

\section{Study population}

The source population for this epidemiologic cohort study has already been described in detail (1-3). It is composed of all people involved in a motor vehicle crash who sustained a whiplash injury in 1987 in Québec and who submitted a claim for compensation to the Société de l'assurance automobile du Québec (SAAQ). The SAAQ is a government body that administers the province's sole universal insurance system, for a population of almost seven million inhabitants, to provide financial compensation to injured motor vehicle accident subjects, whether driver, passenger or bystander. The study subjects were identified from the SAAQ's computerized information systems by searching for individuals with an ICD-9 diagnostic code of 847.0 (sprains and strains of the neck, including whiplash injury) in 1987. The year 1987 was selected as the basis for this study because, in that year, the SAAQ achieved complete coding of claimant injury data by trained professional medical archivists.

A historical cohort was defined as subjects who received some form of compensation from the SAAQ. The date of entry into the cohort was defined as the date of the crash. The exit date from the cohort was the earliest of either the date on which the whiplash subject's file was closed by the SAAQ or May 1993. Sociodemographic factors, namely gender, age, area of residence, marital status, employment status, net income and number of dependents of the whiplash subject were available for this cohort directly from the SAAQ's computerised databases. In addition, information on the presence of multiple injuries besides whiplash at the time of the crash was available.

\section{Cohort for signs and symptoms}

The cohort for signs and symptoms was defined as all subjects of the cohort who did not have other injuries besides whiplash at the time of the crash. Data on symptoms for these subjects were obtained from the medical charts of all 2,843 subjects identified in this cohort. Data on all signs and symptoms noted in the charts, corresponding to all visits to a physician, an emergency room or a hospital following the crash, were coded and classified.

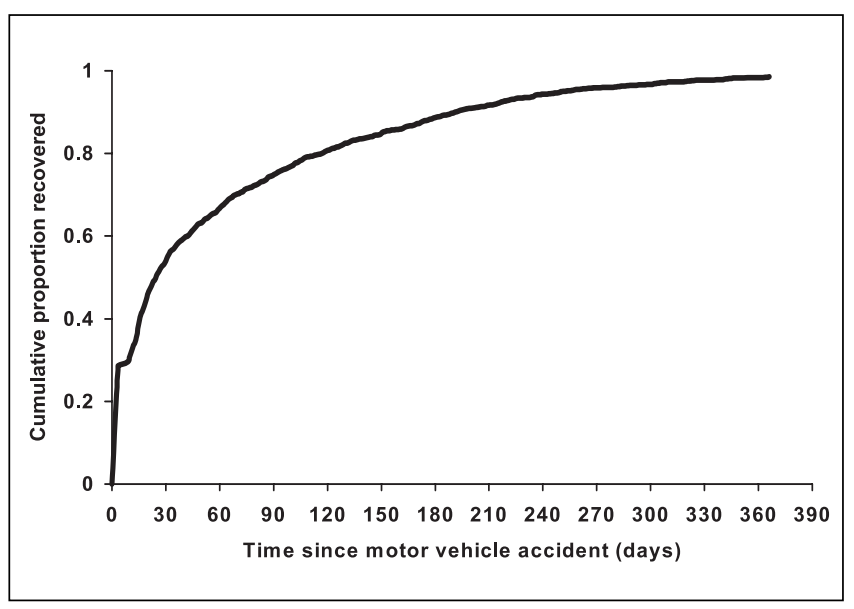

Figure 1) Overall one-year KAPLAN-MEIER cumulative recovery curve for the entire cohort of whiplash patients

\section{Cohort for crash-related factors}

The crash-related cohort was defined as all subjects of the cohort for whom a police report had been filled out at the time of the crash. This report provided data on accident-related factors, namely severity, type of vehicle occupied by the subject, position of subject in the vehicle, type of accident, seatbelt use, direction of collision, number of vehicles involved, and the authorized speed limit in the accident location.

\section{Outcome}

The outcome of interest, for both cohorts, was the length of time the subject took to recover from the whiplash injury. This was measured as the time between the date of the crash and the last date for which compensation to replace regular income was made by the SAAQ.

\section{Data Analysis}

Recovery time was analyzed using methods for survival data. Cumulative recovery curves were estimated by the KAPLANMEIER method and the proportional hazards model was used to estimate rate ratios of recovery from whiplash simultaneously for the prognostic factors.

\section{RESULTS}

There were 4,766 people who submitted claims for compensation for a whiplash injury following a motor vehicle crash in 1987 in Quebec. Of these, the 3,014 who had a police report that contained data on crash-related factors make up the cohort for crash-related prognostic analyses. Among the 4,766, there were 2,627 subjects who only had a whiplash injury and who therefore formed our study cohort for signs and symptoms.

\section{Cohort for signs and symptoms}

The 2,627 cohort members were on average 36 years old, $64 \%$ were female, $53 \%$ were married or living in common-law, $77 \%$ were living with no dependents and, among those with data on employment status, $58 \%$ were working full-time. The KAPLAN-MEIER recovery curve for the entire cohort in Figure 1 shows that the median recovery time is 32 days, $26 \%$ of subjects recovered within one week of the crash and $12 \%$ still had not recovered six months after the crash.

The list of all signs and symptoms reported at the initial visit after the crash is given in Table 1, along with the crude and adjusted rate ratios of recovery relative to the absence of the sign or symptom. The most frequent signs and symptoms are neck pain on palpation, decreased neck mobility, headache and neck pain on mobilisation, with over $10 \%$ prevalence. Visual or ear, nose and throat (ENT) problems, anxiety or insomnia, dizziness or vertigo, and loss of consciousness were the least frequent symptoms. The crude and adjusted rate ratios of recovery indicate that the neurological symptoms are the most predictive of a lower chance of recovery.

Table 2 displays the results of a stepwise multivariate analysis that determined that, among all signs and symptoms, neck pain on palpation, muscle pain, pain or numbness radiating from neck to arms or hands or to shoulders, and headache were the only five that, independently and adjusted for age and gender, had a significant contribution toward a slower recovery. 
TABLE 1

Symptoms at the time of the accident along with crude and adjusted rate ratios of recovery

\begin{tabular}{lccccc}
\hline Symptom & Number* & Crude & Adjusted & $95 \% \mathbf{C l}$ & P \\
\hline Rheumatological signs & & & & & \\
Neck pain on palpation & 305 & 0.85 & 0.86 & $0.77-0.99$ & 0.04 \\
Tenderness on palpation & 247 & 0.88 & 0.93 & $0.81-1.07$ & 0.33 \\
Decreased neck mobility & 308 & 0.89 & 0.98 & $0.86-1.11$ & 0.72 \\
Neck pain on mobilization & 272 & 0.87 & 0.94 & $0.83-1.08$ & 0.38 \\
Rheumatological symptoms & & & & & \\
Muscle pain & 232 & 0.80 & 0.86 & $0.76-1.00$ & 0.05 \\
Muscle stiffness & 157 & 0.89 & 0.92 & $1.78-1.09$ & 0.34 \\
Muscle spasm & 200 & 0.90 & 0.93 & $0.80-1.08$ & 0.34 \\
Neurological symptoms & & & & & \\
Pain or numbness radiating from neck to: & & & \\
Back or chest & 348 & 0.90 & 0.97 & $0.84-1.13$ & 0.68 \\
Arms or hands & 88 & 0.64 & 0.68 & $0.55-0.89$ & 0.01 \\
Shoulders & 186 & 0.79 & 0.86 & $0.75-1.04$ & 0.13 \\
Headache & 310 & 0.78 & 0.82 & $0.72-0.94$ & 0.01 \\
Non-radiating numbness & 120 & 0.66 & 0.80 & $0.60-1.07$ & 0.13 \\
Dizziness or vertigo & 55 & 0.86 & 0.99 & $0.75-1.31$ & 0.96 \\
Loss of consciousness & 54 & 0.76 & 0.84 & $0.64-1.11$ & 0.23 \\
Visual and ENT problems & 20 & 0.83 & 1.03 & $0.65-1.65$ & 0.90 \\
Anxiety or insomnia & 43 & 0.67 & 0.82 & $0.62-1.14$ & 0.10 \\
\hline
\end{tabular}

${ }^{*}$ Do not add up to $N=2628$ since subjects could have had multiple symptoms. ENT Ear nose and throat
TABLE 2

Crude and adjusted rate ratios of recovery for the significant signs and symptoms reported at the first physician contact after the accident

\begin{tabular}{lcccccc}
$\begin{array}{l}\text { Signs or } \\
\text { symptoms }\end{array}$ & Number Per cent & $\begin{array}{c}\text { Crude } \\
\text { rate ratio }\end{array}$ & $\begin{array}{c}\text { Adjusted }^{*} \\
\text { rate ratio }\end{array}$ & $\mathbf{9 5 \%} \mathbf{~ C l}$ \\
\hline $\begin{array}{l}\text { Neck pain } \\
\text { on palpation }\end{array}$ & 247 & $9.4 \%$ & 0.85 & 0.85 & $.0 .76-0.96$ \\
$\begin{array}{l}\text { Muscle pain } \\
\text { Pain or numbness radiating from neck to: }\end{array}$ & 232 & $8.8 \%$ & 0.80 & 0.85 & $0.74-0.97$ \\
\multicolumn{2}{l}{$\begin{array}{l}\text { Arms or hands } \\
\text { Shoulders }\end{array}$} & 88 & $6.2 \%$ & 0.64 & 0.64 & $0.55-0.76$ \\
Headache & 186 & $7.1 \%$ & 0.79 & 0.83 & $0.71-0.97$ \\
\hline
\end{tabular}

*Adjusted for age, gender and one another

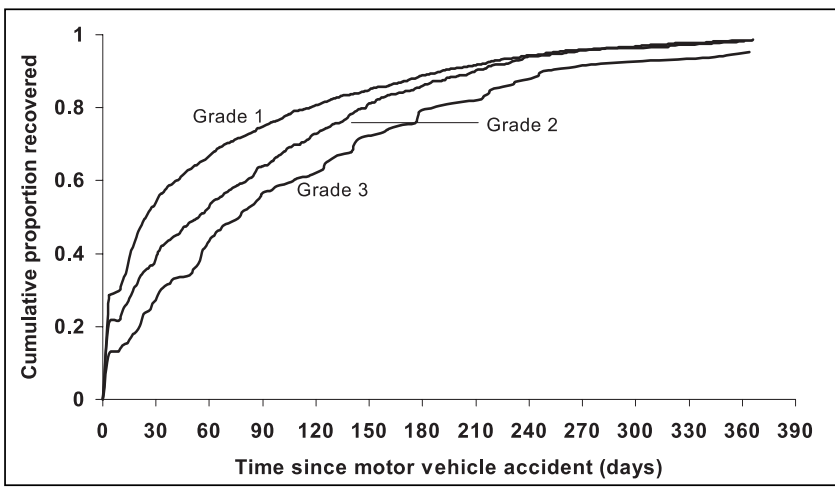

Figure 2) One-year cumulative recovery curve by the three grades of the Quebec classification of whiplash severity

TABLE 3

Crude and adjusted rate ratios of recovery according to the Quebec classification of signs and symptoms at the time of the crash

\begin{tabular}{|c|c|c|c|c|c|c|}
\hline Grade & Definition & Number & Per cent & $\begin{array}{c}\text { Crude } \\
\text { rate ratio }\end{array}$ & $\begin{array}{l}\text { Adjusted* } \\
\text { rate ratio }\end{array}$ & $95 \% \mathrm{Cl}$ \\
\hline \multirow[t]{2}{*}{$\overline{1}$} & Neck complaint of pain, stiffness or tenderness with: & & & & & \\
\hline & No physical signs or symptoms & 1743 & 66.4 & 1.00 & 1.00 & Reference \\
\hline 2 & Musculoskeletal signs or symptoms & 755 & 28.7 & 0.83 & 0.82 & $0.75-0.89$ \\
\hline 3 & Neurological signs or symptoms & 129 & 5 & 0.62 & 0.61 & $0.51-0.73$ \\
\hline
\end{tabular}

${ }^{*}$ Adjusted for age and gender

The signs and symptoms were regrouped according to the proposed Quebec classification of WAD (5). Table 3 displays the rate ratios of recovery for the various grades of this classification. The majority of subjects are classified as grade $1(66.4 \%)$, and only $5 \%$ are classified as grade 3 , which corresponds to neck complaint involving neurological signs. The rate of recovery, adjusted for age and gender, decreases with worsening grade, with rate ratios of 0.82 for grade 2 and 0.61 for grade 3 relative to grade 1 . The KAPLAN-MEIER recovery curve for each of the three grades of WAD is shown in Figure 2. The cumulative probability of recovery decreases with the grade. The median recovery time was 25 days for grade 1, 54 days for grade 2 and 76 days for grade 3 . One year after their crash, $4.8 \%$ of grade 3 subjects still had not recovered, compared with only $1.8 \%$ of grade 2 subjects and $1.4 \%$ of grade 1 subjects.

Figure 3 displays the predicted recovery curves for two extreme groups defined by the prognostic factors of Table 3, characterised by two extreme values of age, namely 20 and 60 years. The slowest recovery is for female subjects age 60 with all significant signs and symptoms, namely neck pain on palpation, muscle pain, and pain or numbness radiating from neck to arms or hands, or shoulders as well as headache. The fastest recovery is for male subjects age 20 with none of these five signs or symptoms. By 60 days after the crash, for example, only $19 \%$ of the slow recovery group will have recovered compared with $77 \%$ of the fast recovery group. The median (the time at which $50 \%$ of subjects recover) is 17 days for the former group and 262 days for the latter.

Figure 4 displays the corresponding curves using the rate ratios of Table 4 for the Quebec classification of whiplashassociated disorders, contrasting the slow recovery group of 60 year old females with grade 3 classification with the faster recovery group of 20-year old males with grade 1 . Here, at 60 days, $35 \%$ of the first group compared with $76 \%$ of the second will have recovered by that time. The median recovery time is 17 days for the first group and 123 days for the second. 


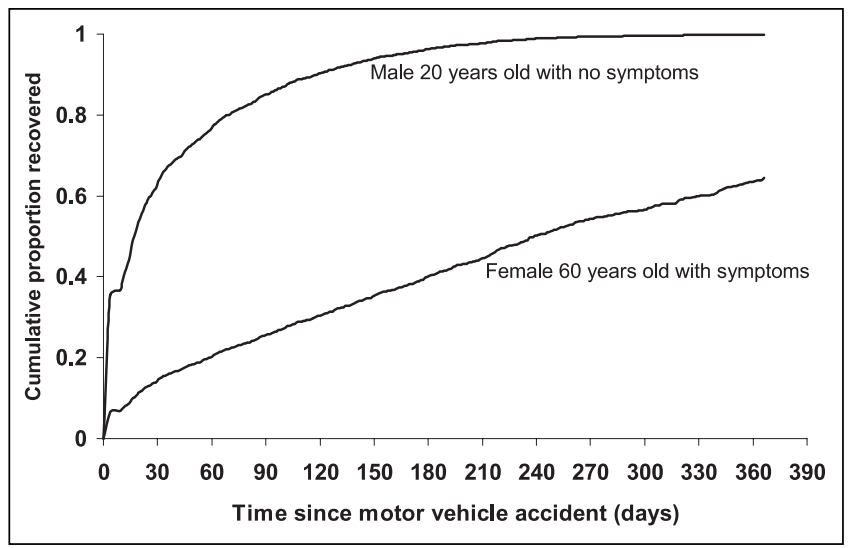

Figure 3) Predicted cumulative recovery curves according to signs and symptoms for subjects with slowest recovery (female gender, age 60, with neck pain on palpation, headache, paresthesia and pain or numbness radiating from neck to arms or hands) and fastest recovery (male gender, age 20, none of the four signs or symptoms)

TABLE 4

Rate of recovery by sociodemographic factors

\begin{tabular}{|c|c|c|c|c|}
\hline & \multicolumn{2}{|c|}{$\begin{array}{c}\text { Whiplash } \\
\text { only }(n=1551)\end{array}$} & \multicolumn{2}{|c|}{$\begin{array}{l}\text { Whiplash and other } \\
\text { injuries ( } n=1259)\end{array}$} \\
\hline & $\mathrm{N}$ & Rate/100/day & & Rate/100/day \\
\hline \multicolumn{5}{|l|}{ Gender } \\
\hline Female & 988 & 1.25 & 678 & 1.06 \\
\hline Male & 563 & 1.67 & 581 & 1.06 \\
\hline \multicolumn{5}{|l|}{ Age (years) } \\
\hline$<35$ & 827 & 1.62 & 743 & 1.30 \\
\hline $35-54$ & 582 & 1.20 & 393 & 0.90 \\
\hline$>55$ & 142 & 1.08 & 123 & 0.71 \\
\hline \multicolumn{5}{|l|}{ Number of dependents } \\
\hline None & 1183 & 1.56 & 993 & 1.16 \\
\hline One or more & 368 & 1.00 & 266 & 0.82 \\
\hline \multicolumn{5}{|l|}{ Marital status } \\
\hline Married/cohabiting & 789 & 1.18 & 582 & 0.95 \\
\hline Other & 762 & 1.65 & 677 & 1.20 \\
\hline \multicolumn{5}{|l|}{ Employment status } \\
\hline Full-time & 654 & 1.16 & 548 & 1.01 \\
\hline Others & 500 & 0.95 & 448 & 0.79 \\
\hline Unknown & 397 & 9.97 & 263 & 3.75 \\
\hline
\end{tabular}

Cohort for crash-related factors

The cohort for crash-related factors contained 204 subjects who had a recurrence and were excluded, leaving 2,810 subjects for the analysis of recovery rates. Compared with the excluded subjects, these 2,810 subjects were of similar age, and consisted of fewer females (60\% versus 67\%), fewer married subjects ( $49 \%$ versus $56 \%$ ), and more subjects employed fulltime ( $46 \%$ versus $40 \%)$.

The overall recovery rate for subjects with whiplash only was 1.37 per 100 subjects per day, while it was 1.06 per 100 per day among subjects with other injuries as well. Table 4 presents the characteristics of the cohort members, stratified by the presence $(\mathrm{N}=1,259)$ or not $(\mathrm{N}=1,551)$ of other injuries besides whiplash, and the respective crude rates of recovery per day per 100 subjects by the sociodemographic factors. Table 5 provides the corresponding rates for the crash-related factors. The

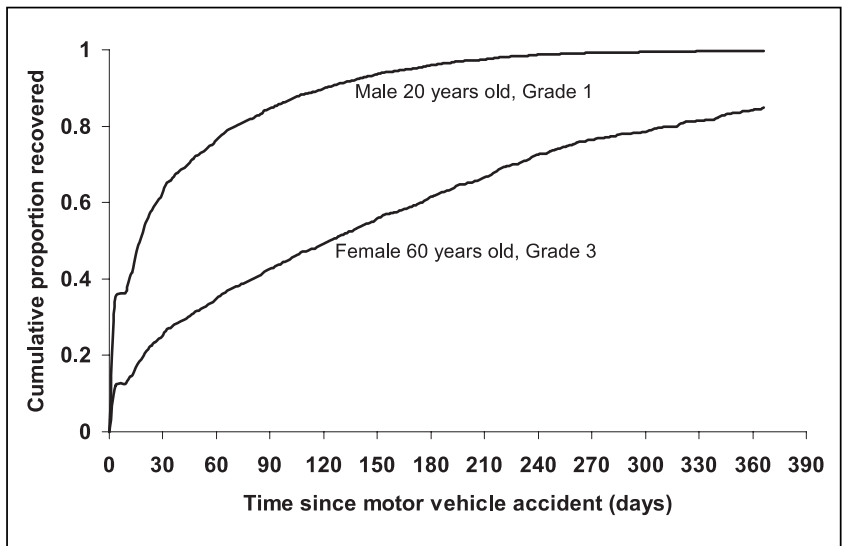

Figure 4) Predicted cumulative recovery curves according to the Quebec classification of whiplash severity for subjects with slowest recovery (female gender, age 60, Grade 3) and fastest recovery (male gender, age 20, Grade 1)

TABLE 5

Rate of recovery by collision-related factors

\begin{tabular}{|c|c|c|c|c|}
\hline & \multicolumn{2}{|c|}{$\begin{array}{c}\text { Whiplash only } \\
(n=1551)\end{array}$} & \multicolumn{2}{|c|}{$\begin{array}{l}\text { Whiplash and other } \\
\text { injuries }(n=1259)\end{array}$} \\
\hline & $\mathbf{N}$ & Rate/100/day & $\mathbf{N}$ & Rate/100/day \\
\hline \multicolumn{5}{|l|}{ Vehicle type } \\
\hline Car or taxi & 1424 & 1.40 & 1068 & 1.11 \\
\hline Truck or bus* & 127 & 1.18 & 191 & 0.88 \\
\hline \multicolumn{5}{|l|}{ Function of subject } \\
\hline Driver & 1209 & 1.41 & 918 & 1.13 \\
\hline Passenger/pedestrian & 342 & 1.27 & 341 & 0.93 \\
\hline \multicolumn{5}{|l|}{ Collision with } \\
\hline Moving object & 1308 & 1.34 & 891 & 1.08 \\
\hline Stationary object & 243 & 1.60 & 368 & 1.04 \\
\hline \multicolumn{5}{|l|}{ Direction of collision } \\
\hline Rear-end & 601 & 1.29 & 249 & 1.06 \\
\hline $90^{\circ}$ or head-on ${ }^{*}$ & 950 & 1.53 & 1010 & 1.07 \\
\hline \multicolumn{5}{|l|}{ Seatbelt use } \\
\hline Yes & 944 & 1.32 & 753 & 1.14 \\
\hline No & 86 & 1.27 & 164 & 1.01 \\
\hline Unknown & 491 & 1.52 & 342 & 0.96 \\
\hline \multicolumn{5}{|l|}{ Speed limit $(\mathrm{km} / \mathrm{h})$} \\
\hline$<60$ & 915 & 1.38 & 594 & 1.23 \\
\hline$>60$ & 636 & 1.37 & 665 & 0.95 \\
\hline
\end{tabular}

${ }^{*}$ These categories include less than 3\% missing data

recovery rates appear to be systematically lower for subjects with multiple injuries and vary for several of these factors.

Univariate and multivariate analyses of the recovery data using Cox proportional hazards models resulted in the crude and adjusted rate ratio estimates shown in Table 6 for subjects with whiplash only, as well as for subjects who have whiplash along with other injuries. For subjects who had a whiplash injury only, female gender, older age, larger number of dependents, married status, not being employed full-time, being in a truck or bus, being a passenger, collision with a moving object, and colliding head-on or sideways are associated with a significantly lower likelihood of recovery. For example, this model indicates that, all other factors being equal, the likelihood of 
TABLE 6

Adjusted rate ratios of recovery, among the 1,551 subjects with whiplash only and the 1,259 subjects with other injuries besides whiplash, estimated using a proportional hazards model for all socio-demographic and crashrelated factors

\begin{tabular}{lcccc}
\hline & \multicolumn{2}{c}{ Whiplash only } & \multicolumn{2}{c}{$\begin{array}{c}\text { Whiplash and } \\
\text { other injuries }\end{array}$} \\
Prognostic factor & Rate ratio & $\mathbf{9 5 \%} \mathbf{~ C l}$ & Rate Ratio & $\mathbf{9 5 \%} \mathbf{~ C l}$ \\
\hline Female gender & 0.86 & $0.77-0.96$ & 0.91 & $0.81-1.03$ \\
Age (per decade) & 0.86 & $0.83-0.90$ & 0.90 & $0.86-0.94$ \\
One or more dependent & 0.84 & $0.74-0.96$ & 0.89 & $0.77-1.04$ \\
Married or cohabiting & 0.95 & $0.85-1.06$ & 0.96 & $0.85-1.09$ \\
Not employed full-time & 0.86 & $0.76-0.98$ & 0.88 & $0.77-1.00$ \\
Fatal or severe collision & 0.96 & $0.79-1.16$ & 0.67 & $0.57-0.78$ \\
Truck or bus & 0.48 & $0.39-0.59$ & 0.55 & $0.45-0.67$ \\
Passenger & 0.85 & $0.74-0.97$ & 0.81 & $0.70-0.94$ \\
Collision with & 0.84 & $0.72-0.99$ & 0.92 & $0.80-1.06$ \\
$\quad$ moving object & & & & \\
Rear-end collision & 0.85 & $0.76-0.95$ & 1.01 & $0.87-1.17$ \\
Seatbelt use & 0.87 & $0.69-1.10$ & 1.03 & $0.87-1.23$ \\
Speed limit $\geq 60 \mathrm{~km} / \mathrm{h}$ & 0.99 & $0.89-1.11$ & 0.93 & $0.82-1.05$ \\
\hline
\end{tabular}

recovery from whiplash at any point in time is $15 \%$ lower for passengers than drivers $(\mathrm{RR}=0.85 ; 95 \% \mathrm{CI}$ : 0.74-0.97) and for every decade increase in age, the likelihood of recovery decreases by $14 \%(\mathrm{RR}=0.86 ; 95 \% \mathrm{CI}$ : 0.83-0.90). For subjects who had other injuries besides whiplash, the trends are similar, but fewer factors demonstrate statistical significance. Here, older age, not being employed full-time, collision severity, being in a truck or bus, and being a passenger are associated with a significantly lower likelihood of recovery.

For patients with a whiplash injury only, the prediction score of recovery was computed from the seven significant factors presented in Table 6 . The prediction score is the sum of $1 \mathrm{~s}$ or Os respectively for the presence or absence of: female sex, one or more dependents, not employed full-time, crash in a bus or truck, passenger, collision with a moving object, collision at $90^{\circ}$ or head-on, as well as of $0,1,2,3,4$ respectively for age less than 30, 30-39, 40-49, 50-59 and 60 and over. This scheme assumes equal weights for each factor, despite the fact that a crash in a truck or bus should have received greater weight. The resulting score ranges from 0 to 11 . Figure 5 displays the recovery curves for three groups of subjects with a whiplash injury only. These three groups are defined by prediction scores ranging from $0-2,3-5$, and $6-11$. The quickest recovery profile is for the group of 375 subjects with prediction scores of $0-2$, while the slowest recovery is for the group of 332 subjects with a score $6-11$. At 60 days, for example, $74 \%$ of subjects with a score of $0-2$ will have recovered, while only $43 \%$ of subjects with a score of 6-11 will have recovered by that time. The median recovery time is 19 days for the former group and 71 days for the latter.

\section{DISCUSSION}

The multivariate regression analysis of rate of recovery revealed that the socio-demographic and crash-related factors that independently lead to a poorer prognosis of whiplash injury include additional injuries besides whiplash, female gen-

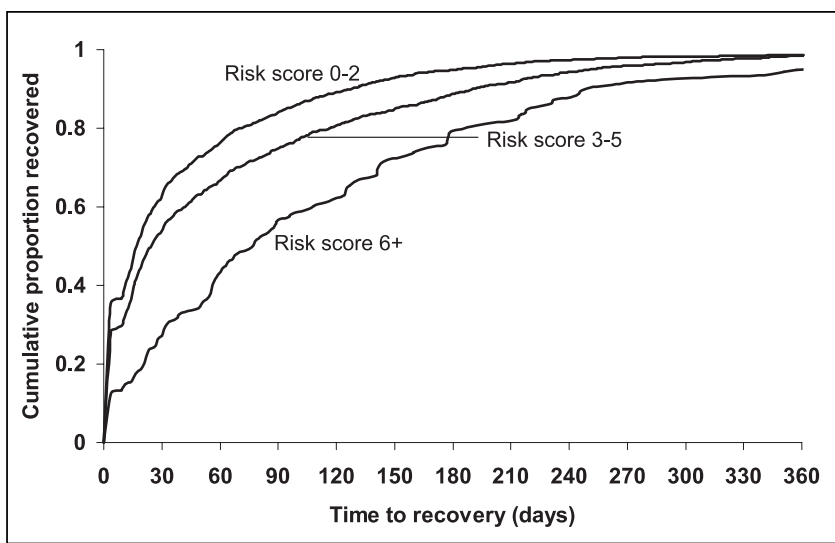

Figure 5) One year cumulative recovery curves among subjects with a whiplash injury alone according to the prediction score: 0-2 (fastest recovery profile), 3-5 (average recovery profile) and 6-11 (slowest recovery profile). The prediction score is the sum of $1 \mathrm{~s}$ or 0 s respectively for the presence or absence of female sex, one or more dependent, not employed full-time, crash in a bus or truck, passenger, collision with a moving object, collision at 900 or head-on, as well as of $0,1,2,3,4$ respectively for age less than 30,30-39, 40-49, 50-59 and 60 and over.

der, older age, greater number of dependents, being involved in a severe crash, in a vehicle other than a car or taxi, and not wearing a seatbelt. These prognostic factors are powerful since, when used in combination, they can vary the median recovery time from less than 19 days to over 71 days. In contrast, five presenting symptoms lead to a poorer prognosis, namely neck pain on palpation, muscle pain, and pain or numbness radiating from neck to arms or hands, or shoulders as well as headache. These prognostic factors, in addition to age and gender, are more powerful than the crash-related factors since they can vary the median recovery time from as low as 21 days to as high as 262 days. The simple Quebec classification of signs and symptoms into three grades of whiplash severity, based primarily on the presence of musculoskeletal or neurological signs, was able to predict moderately well the patients with respect to their time to recovery, with the median recovery time varying from 17 days to 123 days.

The finding that older age was associated with a longer recovery period is reasonable, since the recovery of elderly whiplash subjects is likely to be both more prolonged and to suffer more setbacks than is the recovery of younger whiplash subjects, and this is consistent with other studies (8). In fact, a reduced capacity for recovery among the elderly has been demonstrated for motor vehicle crash injuries in general $(18,19)$. The finding that having dependents leads to slower recovery, independently of age, is difficult to explain except perhaps from the social perspective, as found for the subjects not employed full-time.

The fact that being in a truck or bus, as opposed to a car or taxi, at the time of the crash is a prognostic factor may reflect the fact that trucks and buses lack certain useful safety features that are incorporated into the design and construction of cars and taxis. Seatbelt use, which has been demonstrated by several authors to increase the occurrence of whiplash injury among motor vehicle occupants who are involved in a collision (11-13), was found to result, although not significantly, in a 
worse prognosis for those who did sustain a whiplash injury. In other words, people who wear seatbelts are more likely to get whiplash if they are in an crash, and they will have a slower recovery than those who sustain a whiplash injury while not wearing a seatbelt. This result is consistent with that of a previous paper by DEANS ET AL. (20) who reported that one year after their crash, $34 \%$ of those whiplash subjects who were wearing a seatbelt still experienced neck pain, while only $20 \%$ of those who had not worn a seatbelt still felt neck pain. Being a passenger, colliding with a moving object and not in a rearend impact are new factors leading to slower recovery and longer disease course.

With respect to signs and symptoms at the time of the crash, the few other studies that assessed their prognostic value have been limited by their small sample size, all less than 100 patients, and other design constraints, with different findings from our study. First, we found that by six months into followup only $12 \%$ of patients still had not recovered, compared with $27 \%$ to over $44 \%$ reported in other studies (8-10). This finding is likely due to the fact that our cohort is population-based and we had precise data on time zero for all subjects. Nevertheless, because subjects with very mild injury may not have proceeded with a claim, the six month recovery rate may in fact be lower than $13 \%$. Second, paresthesia, the presence of neck stiffness and muscle spasm, pain in the upper limbs and back and the general presence of musculoskeletal or neurological signs, were found to be associated with a delay in recovery $(8,16,17)$. Our study permitted the uncovering of other symptoms and signs, as well as more specific profiles than simply "musculoskeletal or neurological signs" on which the Quebec classification is based on, that provide more precise prognosis assessment.

The coding and entry of data into the SAAQ's computerized databases, which is usually of concern in claims databases, has been shown to be very reliable (21) and is therefore not considered an important source of error or potential bias in this study. Nevertheless, the design of the study has some limitations. One limitation of the SAAQ data is that the direction of collision, a potentially important prognostic factor (22), could not be identified precisely for each crash victim. For example, in the case of rear-end collisions, it was not always clear from the database information whether the victim was in the front car (i.e., hit from behind) or in the rear car (i.e., frontal collision). Whether or not the whiplash victim's neck was turned at the time of the collision was also not known. Furthermore, information regarding the presence or absence of safety features (e.g., properly positioned head restraints) was not recorded in the SAAQ's databases. These features may help to reduce injury severity, thereby improving prognosis.

Other prognostic factors discussed in the literature which could not be assessed in this study include medico-legal factors (which are not applicable under Québec's universal insurance system) (23-25) and the physical, emotional, and social characteristics of the whiplash victim $(6,16,24,26-28)$. A recent study in Saskatchewan, a province of Canada of one million inhabitants, showed in analysing a natural experiment that the change in policy from a tort system to a no-fault insurance system in 1995 reduced by $35 \%$ the rate of new claims and by $50 \%$ the duration of claims. The rate and duration of claims for whiplash injuries are now lower in that province, but still higher than the corresponding figures in Quebec, another Canadian province that has had a no-fault system in place for decades (29).

With respect to external validity, despite its large sample size and population-based nature, this study may have included some subjects who did not actually have whiplash. For example, there may have been a tendency for physicians to diagnose any neck pain as whiplash if a more specific diagnosis could not be made. Strictly speaking, the term "whiplash" was originally intended to describe the mechanism of injury caused by the rapid hyper-extension and flexion of the muscles of the neck, as commonly experienced by motor vehicle occupants involved in rear-end collisions (4). However, the word whiplash has since entered into common usage to describe injury to the soft tissue of the neck or cervical spine resulting from motor vehicle crashes, regardless of the specific mechanism by which the injury occurred, and is essentially used in this way in the present study. The primary reason for the 1,743 of the 4,766 claims who did not have an accident report was that these crashes were mostly minor and the police were either not called to the scene or were not required to fill out a report (if the vehicle damages are under \$500 CAD and there were no important injury to any passenger). This should tend to underestimate the rates of recovery over time, but should not affect the rate ratios of recovery unless the risk factor profile of this excluded group is different from that of the cohort. Unfortunately, we do not have the data to verify this. Moreover, the SAAQ's regulation that crash subjects are not eligible for per diem income replacement compensation if they are able to return to work or their usual activities within seven days of their crash also may have affected the external validity of the study. This regulation may have resulted in the exclusion of a sub-population of individuals with mild whiplash injuries, except those who filed a claim for compensation of one or more types of expenses related to the crash (e.g., replacement of damaged clothing).

The outcome measure used in this study was subject to different sources of measurement error and misclassification. Time to recovery of whiplash patients was measured using administrative compensation data. It is possible that many whiplash subjects may have continued to live with pain or discomfort for some time after resuming their usual activities or, conversely, that some may have continued to be compensated although their pain and discomfort had disappeared. This is unlikely to have been substantial, however, because of the close monitoring of these subjects by physicians who must report the progress to the SAAQ. Nevertheless, from a pragmatic perspective, compensation time is a relevant outcome since the resulting indirect cost of whiplash is almost $\$ 4,000$ (1987 CAD) per subject and $43 \%$ of the total cost is generated by the $12 \%$ of subjects with more than six months of compensation time (1). We only extracted the signs and symptoms that were reported in the medical charts. In view of the legal status of the SAAQ, the physicians who completed the charts were required to note all relevant information for the diagnosis and subsequent compensation. As a result, the medical charts were quite complete and missing signs and symptoms would have occurred only from misdiagnosis and not carelessness. Third, despite its large sample size and population-based nature, this study excluded 
$5 \%$ of subjects who did not actually have whiplash but were coded as such. We do not know how many patients of the 25,000 claimants to the SAAQ in 1987 actually had whiplash and should have been part of this cohort, but were not coded as such. We suspect that this number is small since on the contrary, there may have been a tendency for physicians to diagnose any neck pain as whiplash if a more specific diagnosis could not be made. Finally, the prediction score we developed must be validated in another sample of subjects. Although it

\section{REFERENCES}

1. Suissa S, Harder S, Veilleux M. The Quebec whiplash-associated disorders cohort study. Spine 1995;20:12S-20S.

2. Harder S, Veilleux M, Suissa S. The effect of socio-demographic and crash-related factors on the prognosis of whiplash.

J Clin Epidemiol 1998;51:377-84

3. Suissa S, Harder S, VeilleuX M. The relation between initial symptoms and signs and the prognosis of whiplash. Eur Spine J 2001;10:44-9.

4. Crowe HE. Injuries to the cervical spine. San Francisco, Western Orthopaedic Association, 1928.

5. Spitzer WO, Skovron ML, Salmi LR, Cassidy JD, Duranceau J, SuISSA S, ZEISS E. Scientific monograph of the Quebec Task Force on Whiplash-Associated Disorders: Redefining "whiplash” and its management. Spine 1995;20:1S-73S.

6. Miles KA, Maimaris C, Finlay D, Barnes MR. The incidence and prognostic significance of radiological abnormalities in soft tissue injuries to the cervical spine. Skeletal Radiol 1988;17:493-6.

7. LIVINGSTON M. Whiplash injury: Some continuing problems. Humane Med 1993;9:274-81.

8. Radanov BP, di Stefano G, Schnidrig A, Ballinari P. Role of psychosocial stress in recovery from common whiplash. Lancet 1991;338:712-5.

9. Deans GT, McGalliard JN, Rutherford WH. Incidence and duration of neck pain among patients injured in car accidents. Br Med J (Clin Res Ed) 1986;292:94-5.

10. Hildingsson C, Toolanen G. Outcome after soft-tissue injury of the cervical spine. A prospective study of 93 car-accident victims. Acta Orthop Scand 1990;61:357-9.

11. Thomas J. Road traffic accidents before and after seatbelt legislationstudy in a district general hospital. J R Soc Med 1990;83:79-81.

12. BARANCIK JI, KRAMER CF, ThODE HC JR. Epidemiology of motor vehicle injuries in Suffolk County, New York before and after enactment of the New York State seat belt use law. US Department of Transportation National Highway Traffic Safety Administration, 1989

13. Otremski I, Marsh JL, Wilde BR, McLardy Smith PD, NEWMAN RJ. Soft tissue cervical spinal injuries in motor vehicle accidents. Injury 1989;20:349-51.

14. Burke JP, Orton HP, West J, Strachan IM, Hockey MS, FERGUSON DG. Whiplash and its effects on the visual system. appears to discriminate well, this may be typical to this study population and thus the need for replication.

In conclusion, several socio-demographic and crash-related factors, as well as signs and symptoms, are independently associated with a slow and costly recovery from whiplash injury. They are easily measurable at the time of the crash and combined so as to be simply incorporated in intervention programs aimed at early identification and management of whiplash patients with a poor prognosis.

Graefes Arch Clin Exp Ophtalmol 1992;230:335-9.

15. HeISE AP, LASKIN DM, GERVIN AS. Incidence of temporomandibular joint symptoms following whiplash injury. J Oral Maxillofac Surg 1992;50:825-8.

16. NoRRIS SH, WATT I. The prognosis of neck injuries resulting from rear-end vehicle collisions. J Bone Joint Surg Br 1983;65:608-11.

17. GREENFIELD J, ILFELD FW. Acute cervical strain. Evaluation and short term prognostic factors. Clin Orthop 1977;196-200.

18. McCoy GF, Johnston RA, Duthie RB. Injury to the elderly in road traffic accidents. J Trauma 1989;29:494-7.

19. Barancik Ji, Chatterjee BF, Greene-Cradden YC, et al. Motor vehicle trauma in northeastern Ohio. I: Incidence and outcome by age, sex, and road-use category. Am J Epidemiol 1986;123:846-61.

20. Deans GT, Magalliard JN, Kerr M, Rutherford WH. Neck sprain - A major cause of disability following car accidents. Injury 1987;18:10-2.

21. Laberge-Nadeau C, Bienvenu M, Maag U, Bourbeau R. Rapport technique sur l'analyse de la qualité des données des fichiers de la R.A.A.Q. pour fin d'évaluation de la ceinture de sécurité. Publication \# 340. Université de Montréal, Centre de recherche sur les transports, 1984.

22. MACnab I. The "whiplash syndrome". Orthop Clin North Am 1971;2:389-403.

23. Mendelson G. Not "cured by a verdict". Effect of legal settlement on compensation claimants. Med J Aust. 1982;2:132-4.

24. FARBMAN AA. Neck sprain. Associated factors. JAMA 1973;223:1010-5.

25. GOTTEN N. Survey of one hundred cases of whiplash injury after settlement of litigation. JAMA 1956;162:865-7.

26. Hirsch SA, Hirsch PJ, Hiramoto H, Weiss A. Whiplash syndrome. Fact or fiction? Orthop Clin North Am 1988;19:791-5.

27. Foletti GB, Regli F. [Indirect cervical trauma: long-term adverse prognostic factors]. Schweiz Rundsch Med Prax 1987;76:1304-9.

28. BALLA JI. The late whiplash syndrome: A study of an illness in Australia and Singapore. Cult Med Psychiatry 1982;6:191-210.

29. Cassidy JD, Carroll lJ, Cote P, Lemstra M, Berglund A, NYgren A. Effect of eliminating compensation for pain and suffering on the outcome of insurance claims for whiplash injury. N Engl J Med 2000;342:1179-86.

This material was presented at the International Congress on Whiplash Associated Disorders, Berne, Switzerland, March 8 to 10, 2001. The paper appeared originally in the book "Whiplash Associated Disorders" - medical, biomechanical and legal aspects, published by Staempfli Publishers Ltd,

Berne 2002. The paper is published in North America in Pain Research $\mathcal{E}$ Management with the permission of Staempfli Publishers Ltd. 


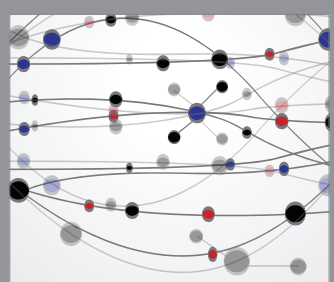

The Scientific World Journal
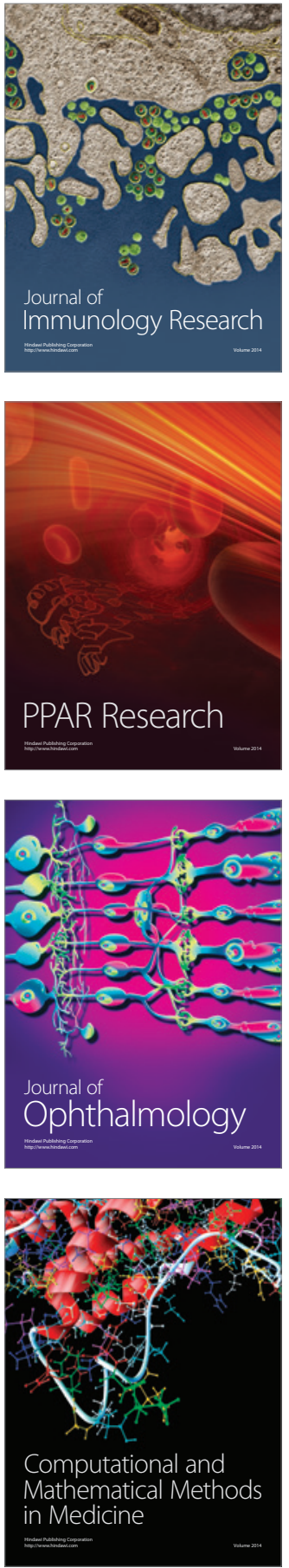

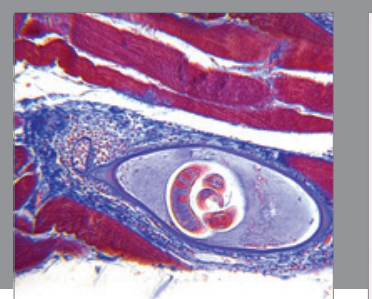

Gastroenterology Research and Practice

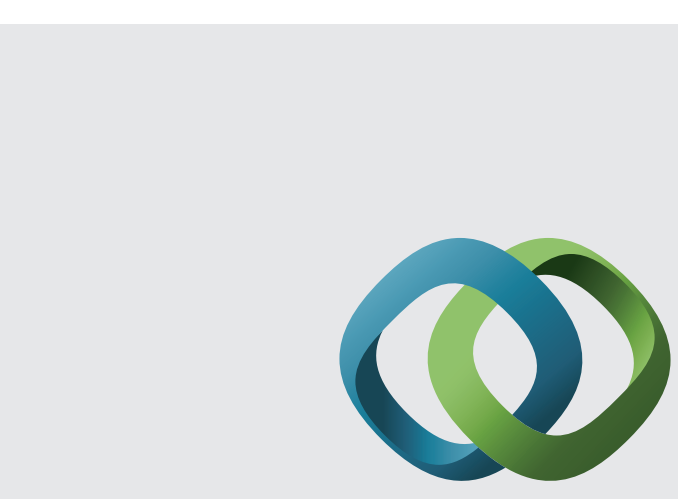

\section{Hindawi}

Submit your manuscripts at

http://www.hindawi.com
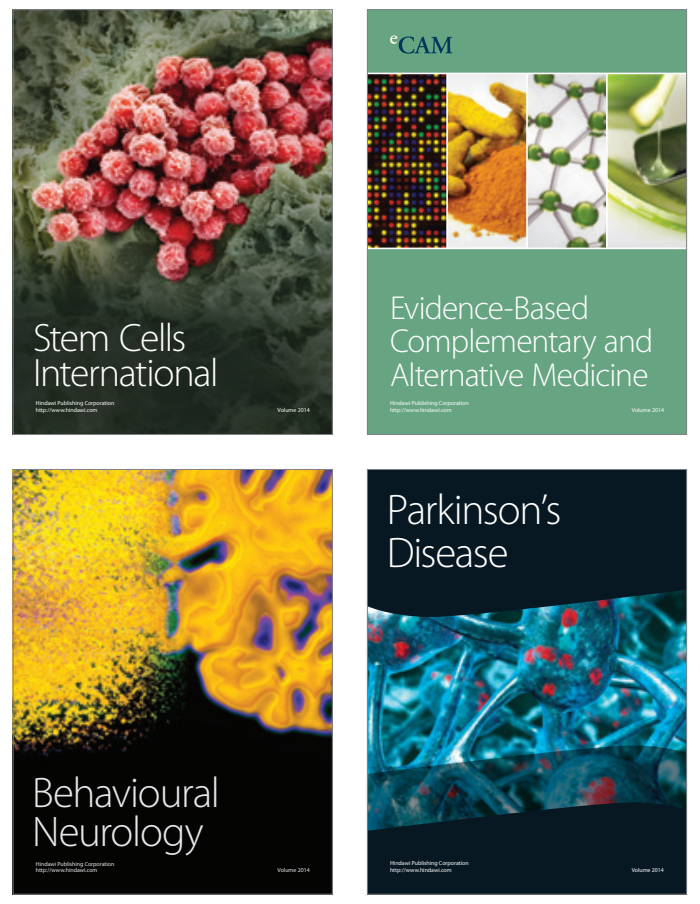
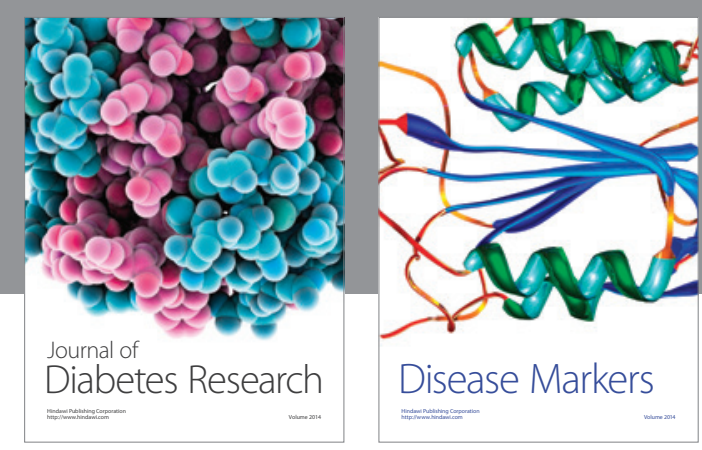

Disease Markers
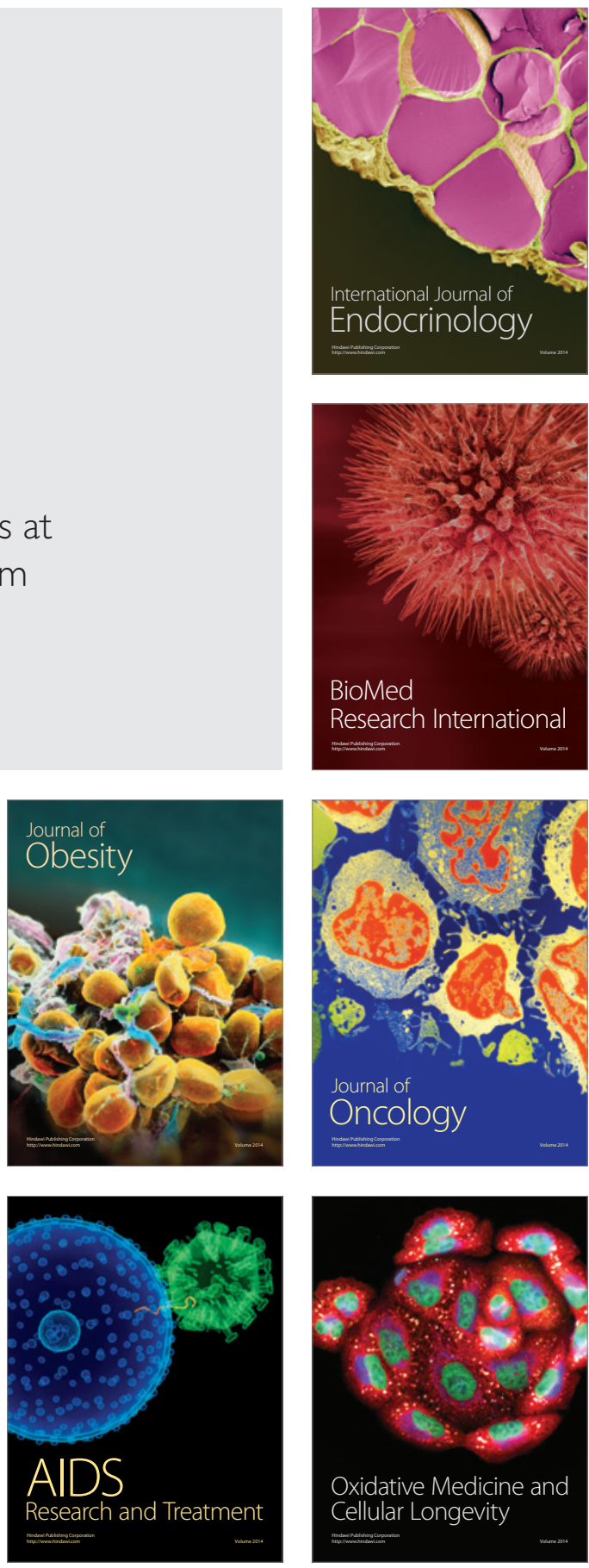